\title{
Who Are Today's Older Adults Going Through a Change in Living Situation?
}

\author{
Hacking Life Shifts 2020
}
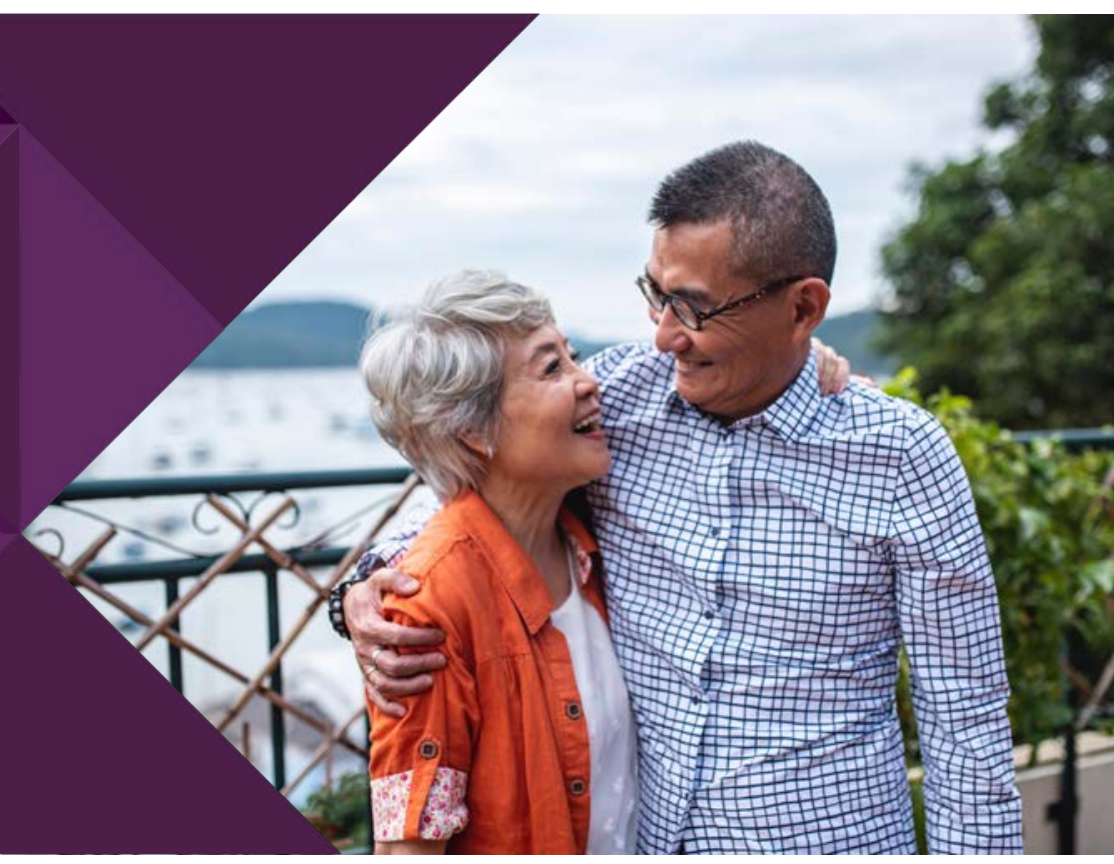

\section{Change in Living Situation: Executive Summary}

Life Shifts don't exist in a vacuum. Many people are experiencing two or more shifts at any given time. This is particularly true of those Changing their Living Situation. This Life Shift has the highest incidence of overlap with other shifts. For example, $42 \%$ of Grandparents, 33\% of Caregivers, 33\% of Career Encorers, and $26 \%$ of Aging Singles are also Changing their Living Situation. For this reason, Change in Living Situation is a middle ground. These people understandably look much like the overall 45-plus US population.

\section{Changes in Living Situation are most likely to coincide with other Life Shifts.}

\section{Change in Living Situation: Health, Wealth \& Self}

This Life Shift is predominantly composed of Boomers, who are slightly older with a mean age of 63.9. Their primary motivation for relocating: downsizing to a home that would require less maintenance. Financial reasons are a secondary motivator; just less than $25 \%$ of those in this group point to finances as the main reason behind their change. Fifty-five percent of those interviewed have already made the move, while $45 \%$ are in the planning stages. Most moves are to a residence they will own, where they will live with someone. It's most likely to be a house as opposed to an apartment, condo, townhome, or senior community. Fifty-two percent paid (or plan to pay) in full for their new home. Generationally, Xers are most likely to rent, and Boomers are most likely to own.

Boomers are looking to downsize and deal less with home maintenance; they're also motivated by financial factors and better weather. Gen X lists these same motivators, though financial factors rank a bit higher. Qualitative data suggests that safety, security, convenience, and community as the most motivating factors for a move. Most point out that their current situation is not sustainable largely because of the costs and labor of maintenance. They hope that this move will bring them greater peace of mind. 


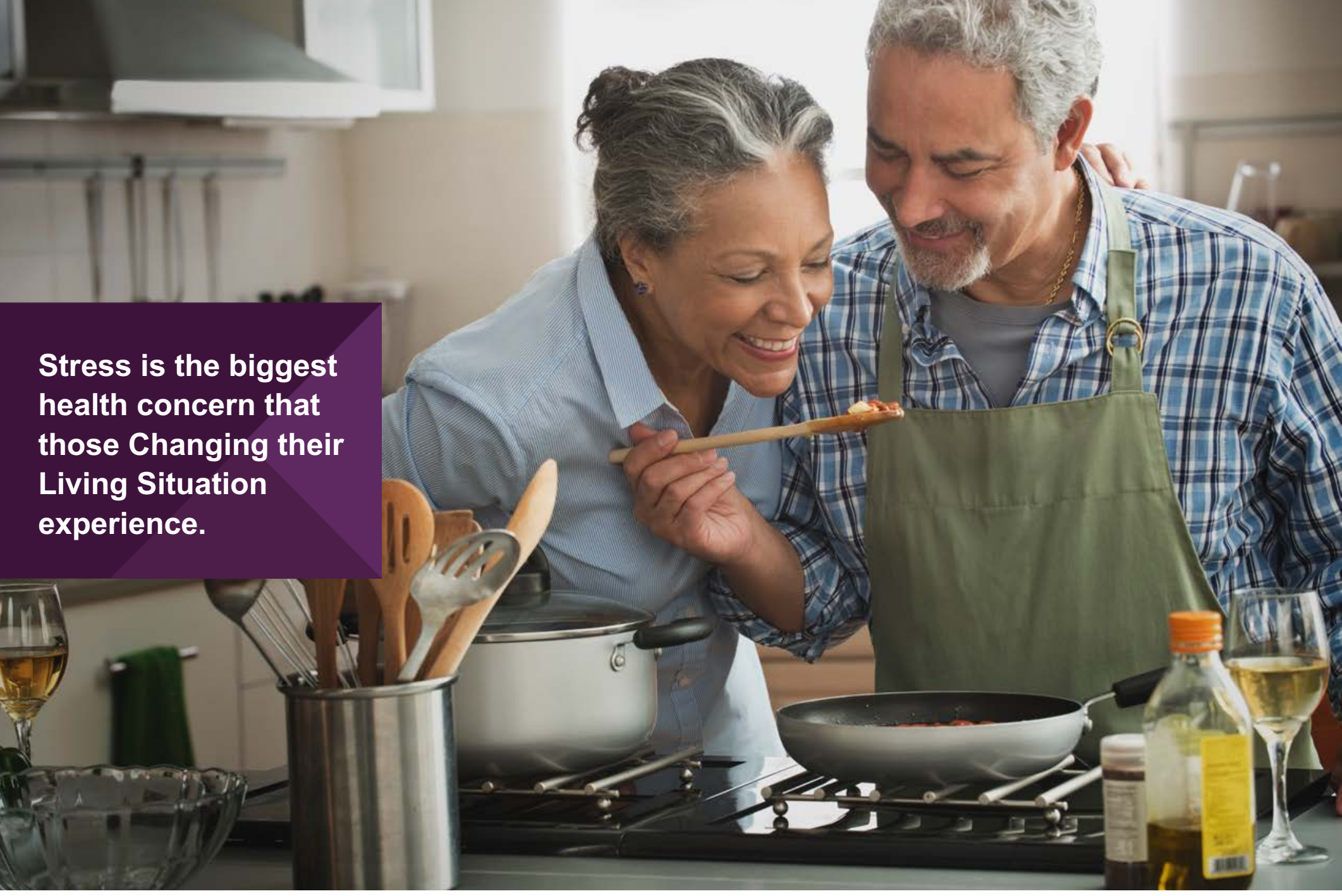

Only $30 \%$ of those Changing their Living Situation report experiencing financial strain as a result of the shift. This number is consistent among those who have moved and those planning to move, suggesting that moving does not solve the financial stress people are experiencing. (It likely also reflects the expenses of moving and getting settled in a new locale.)

Forty-seven percent of Gen Xers in this Life Shift are under at least some financial strain, compared with $30 \%$ of Boomers and only $11 \%$ of Silents. People in this shift report cutting back on living expenses like cable and getting rid of "stuff," while they cook more at home and reduce their entertainment expenses.

Downsizing to a home with less maintenance is the primary motivation for those Changing their Living Situation.

Stress is the biggest health concern that those Changing their Living Situation experience; they worry about making the right choice, while experiencing sleeplessness and feeling fatigued. They feel anxious over what life in their new home will be like. Although a range of emotions accompanies leaving the community in which they've typically lived for many years, those planning their move feel in control, independent, and purposeful. 


\section{Resources for Change in Living Situations}

Those navigating a Change in Living Situation have moderate levels of awareness of products and services that can assist them with finances, physical health, emotional health, and social health. Only $17 \%$ have accessed resources for their physical health, and $13 \%$ have used financial resources. Those who plan to move have a greater awareness of resources than those who already have, reflecting the former being in the process of seeking and accessing resources to make their move.

Prior to moving, older adults are aware of and seek out information about their new community, the cost of living, and size of their prospective residence. Following a move, they're looking for ways to make social connections and learn more about their new community. The top information source for those in this shift is consulting with family members and others close to them for helpful advice. Respondents also look for information in newspapers, magazines, and even blogs. Some also speak with medical professionals relative to their move.

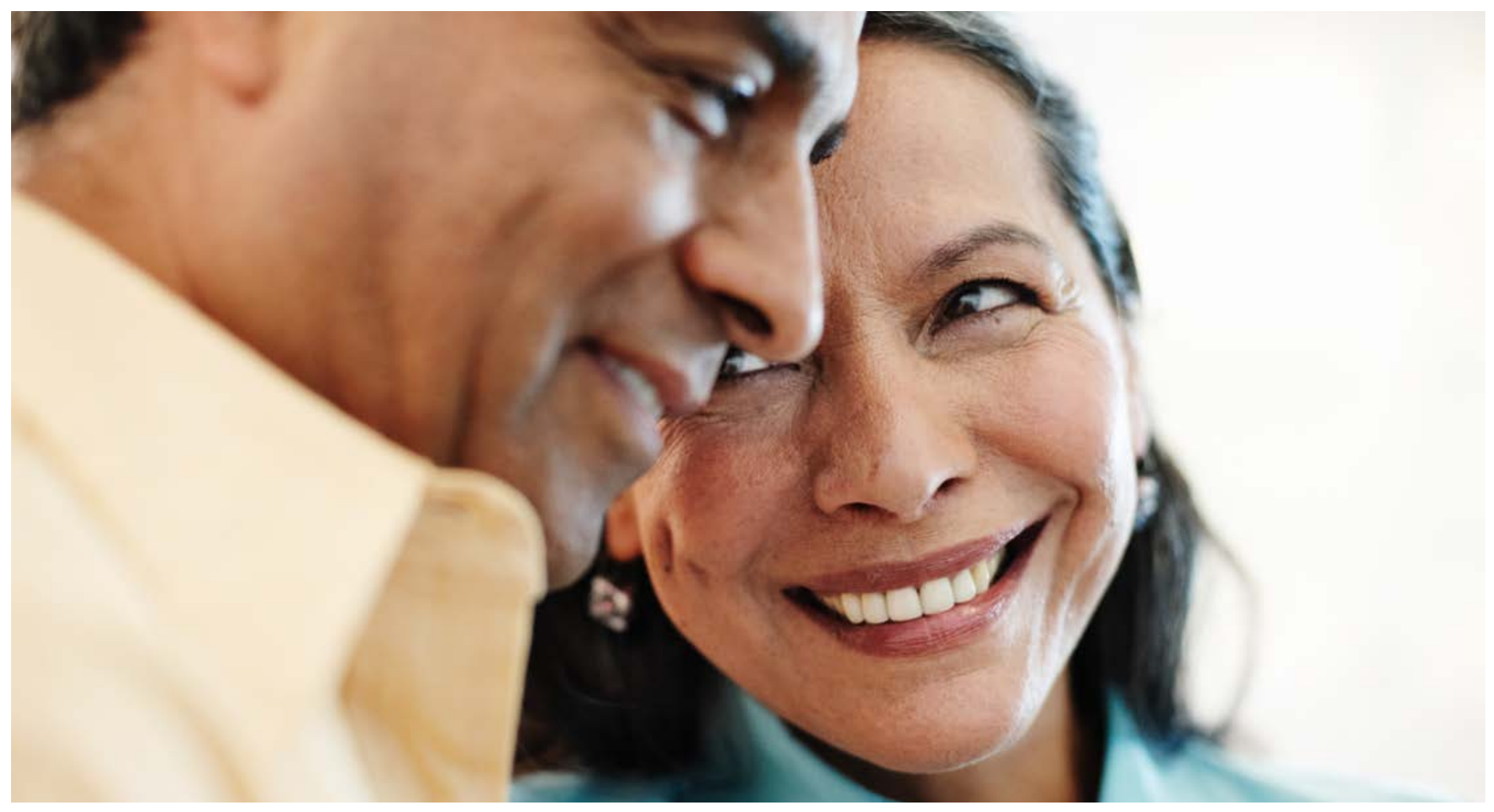

What do those who are Changing their Living Situation buy? Smart technology, including monitoring devices, and insurance products top the list. Furnishings and appliances are relatively low-incidence purchases, considering the number of people moving. While $61 \%$ of these purchases are in-store, $50 \%$ buy online as well; so, even for older movers, the omnichannel intersection of brick-and-mortar and online is critical to understand.

Change in Living Situation is the Life Shift that happens during or as a result of other shifts. While those in this shift look a lot like the general 45-plus population, there are some attitudinal markers that make the shift distinctive. These individuals feel decisive and capable in difficult situations. They also show a sense of independence and renewed purpose as a result of navigating this shift. But they also feel the pressure of staying connected to family members, monitoring their own health, and, of course, financial stress, which inhibits their sense of fulfillment. Just more than $60 \%$ report high levels of fulfillment; those who are older and retired with higher incomes are the most fulfilled among this group. On a positive note, this fulfillment number rises a bit once people have made their move and continues to rise the longer they've been in their new homes. 
